\title{
Performance of an Ocean Energy Conversion System with DFIG Sensorless Control
}

\author{
I. Garrido, ${ }^{1}$ Aitor J. Garrido, ${ }^{1}$ M. Alberdi, ${ }^{1}$ M. Amundarain, ${ }^{1}$ and O. Barambones ${ }^{2}$ \\ ${ }^{1}$ Department of Automatic Control and Systems Engineering, EUITI de Bilbao, University of the Basque Country (UPV/EHU), \\ Rafael Moreno 3, 48013 Bilbao, Spain \\ ${ }^{2}$ Department of Automatic Control and Systems Engineering, EUI de Vitoria-Gasteiz, University of the Basque Country (UPV/EHU), \\ Nieves Cano 12, 01006 Vitoria-Gasteiz, Spain
}

Correspondence should be addressed to I. Garrido; izaskun.garrido@ehu.es

Received 24 February 2013; Accepted 21 May 2013

Academic Editor: Massimo Scalia

Copyright (c) 2013 I. Garrido et al. This is an open access article distributed under the Creative Commons Attribution License, which permits unrestricted use, distribution, and reproduction in any medium, provided the original work is properly cited.

\begin{abstract}
The 2009/28/EC Directive requires Member States of the European Union to adopt a National Action Plan for Renewable Energy. In this context, the Basque Energy Board, EVE, is committed to research activities such as the Mutriku Oscillating Water Column plant, OWC. This is an experimental facility whose concept consists of a turbine located in a pneumatic energy collection chamber and a doubly fed induction generator that converts energy extracted by the turbine into a form that can be returned to the network. The turbo-generator control requires a precise knowledge of system parameters and of the rotor angular velocity in particular. Thus, to remove the rotor speed sensor implies a simplification of the hardware that is always convenient in rough working conditions. In this particular case, a Luenberger based observer is considered and the effectiveness of the proposed control is shown by numerical simulations. Comparing these results with those obtained using a traditional speed sensor, it is shown that the proposed solution provides better performance since it increases power extraction in the sense that it allows a more reliable and robust performance of the plant, which is even more relevant in a hostile environment as the ocean.
\end{abstract}

\section{Introduction}

There is a current need not only for greater energy accessibility but also to prevent that the energy consumption environmental impact grows to the point that causes irreversible damage to the planet. In this sense, the European Parliament has backed up a climate change package which aims to achieve by 2020 a $20 \%$ reduction of greenhouse gas emissions, a $20 \%$ increment in energy efficiency, and a $20 \%$ of renewable share within European Union (EU) countries. At the same time, recent developments have highlighted that relying so heavily on fossil and fission-based energy poses a security, economic, and human threat. The British Petroleum oil spill in the Gulf of Mexico caused extensive damage on the economy and welfare of the region, the "Arab Spring" has triggered oil-price volatility, and Japan's Fukushima nuclear catastrophe has brought about doubts over the role of fission-based energy. In recent studies $[1,2]$, Drs. Jacobson and Delucchi stated that "barriers to a $100 \%$ conversion to wind water and solar power worldwide are primarily social and political, not technological or even economic." Based on their studies, all the world energy needs might be satisfied from wind, water, and solar power, considering 720,000 0.75 MW wave devices. In any case, the advantages are many since it is a clean, free, readily available, and safe source of energy that, even when it currently requires further research, it is called to play a main roll in a near future.

The Spanish Council of Ministers on 11th November 2011 approved the Renewable Energies Plan for 2011-2020. This plan includes the design of new energy scenarios and incorporating the objectives given in the Directive 2009/28/EC of the European Parliament on the promotion of the use of energy from renewable sources, which sets binding minimum targets for the whole of the European Union and for each of the Member States. In particular, this plan highlights the marine energy potential that Spain possesses with special 


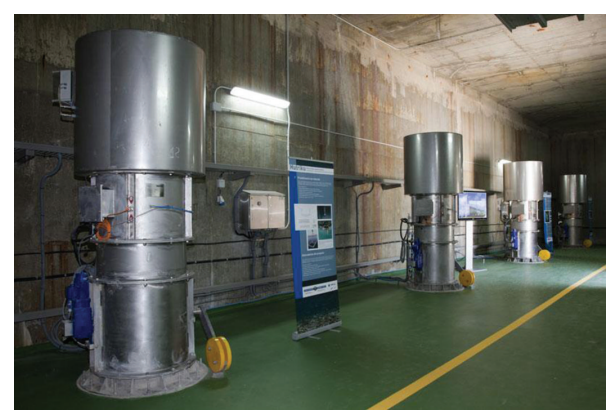

FIgURE 1: OWC for the Nereida project by the EVE.

emphasis in wave energy, with the potential to satisfy $15 \%$ of EU energy demand, cutting $136 \mathrm{MT} / \mathrm{MWh}$ off the $\mathrm{CO}_{2}$ emissions by 2050 . The proposals are directed mainly to the $\mathrm{R} \& \mathrm{D}$ not only of new designs and components aiming to improve equipment fatigue and reduce the cost, but also of demonstration programs for prototypes testing, as well as to develop infrastructure to validate experimental devices. Major efforts are being made in the Basque Country through the Nereida Project, promoted by Basque Energy Board (EVE), which has developed an Oscillating Water Column (OWC) integrated in a breakwater located in Mutriku and involves a $€ 5.7 \mathrm{M}$ investment. The plant consists of 16 turbines, $18.5 \mathrm{~kW}$ each, with an estimated overall power of $296 \mathrm{~kW}$ (see Figure 1). It was inaugurated in July $2011[3,4]$ and produced $200.000 \mathrm{kWh}$ during the first year while it was estimated $600.000 \mathrm{kWh}$ production per year. Although the difference is mainly due to a storm that damaged the control room and kept the facility closed during the best wave months, an improvement in the power generation could highly benefit the system.

In this power plant, the water surface inside a chamber moves up and down under the wave action causing to inhale and exhale air through the opening at the top. The bidirectional air flow is applied to a special kind of turbine, called Wells turbine, which provides unidirectional rotation despite of the air flow direction $[5,6]$. Thus, the Wells turbine transforms the wave potential into mechanical energy that will be transmitted to a double feed induction generator, which feeds AC power to the grid. For that, two pulse-width-modulated three phase converters are connected back to back between the rotor terminal and the utility grid with a DC link. The stator circuit is directly connected to the grid while the rotor winding is connected via slip-rings to the rotor side converter [7].

The OWC system located in Mutriku uses a vector control scheme coupled with cascaded Proportional-Integral-Derivative (PID) controller for current and power loops [8]. This scheme allows power tracking while the Rotor and Grid Side Converters, RSC/GSC, are controlled independently. Besides, it has fault-ride-through (FRT) capabilities and the OWC system also implements a complementary modified antiwind-up PID based valve control for incoming air flow into the turbine [9-11]. The choice of valve control has been mainly determined by the fact that it is the control used in Mutriku. New Grid Codes oblige distributed power-generation systems to remain connected to the power network during the fault to avoid massive chain disconnections so that the implementation of an adequate FRT capability is indispensable in this kind of systems to ensure its stability and uninterrupted operation [12-17].

All mechanical parts should be designed to withstand the ocean hostile environment and it has to be considered that the turbo-generator control requires a precise knowledge of the system parameters and of the rotor speed in particular. In this context, the most suitable option is to remove the mechanical speed sensor at the rotor shaft so as to simplify the hardware, with the consequent reduction in installation and maintenance costs, increment of disturbance rejection, and plant reliability improvement. However, in order to eliminate the speed sensor from the drive, some of the state variables, such as rotor angular velocity and flux, have to be estimated from measured states. Besides, accuracy, robustness, and sensitivity against parameter deviation can be improved by choosing closed loop observers $[18,19]$. Therefore, dynamic performance and steady-state speed accuracy for the lower speed range have been achieved in this particular case considering a closed loop speed observer based in a Luenberger system to estimate the rotor speed from the measured stator voltages and currents $[20,21]$.

After all these considerations and taking into account the cost effectiveness and improved performance that a speed observer can afford, this paper presents a new sensorless vector control scheme in order to improve the power extraction in the Mutriku OWC, whose results can easily be extended to other wave power plants. The rest of the paper is organized as follows. In Section 2 the OWC is presented, and both its modules, the capture chamber, and the turbine that generates energy are explained. Next, in Section 3, the proposed sensorless control scheme is stated. In Section 4, simulation results for a representative case-study comparing different controlled cases have been obtained. And finally, some concluding remarks are presented in the last section.

\section{Mutriku OWC Description}

2.1. Mutriku Wave Model and OWC Capture Chamber. Using data from the Bilbao-Vizcaya exterior buoy of the State Network Ports, the annual average wave height is around $2 \mathrm{~m}$, with period of about $10 \mathrm{~s}$. Statistical study of wave directions reveals the predominance of northeast swell type wave [22, 23]. In order to study regular waves (see also [24]), it is necessary to take into account the spectrum of the wave climate data, that measures the correlation between wave frequency and wave energy, as it may be observed in Figure 2.

This representative spectrum of the wave climate is buoy driven, since it uses a linear wave propagation model to transform measures obtained by an offshore wave rider buoy in deep water to the OWC location in the coast. 


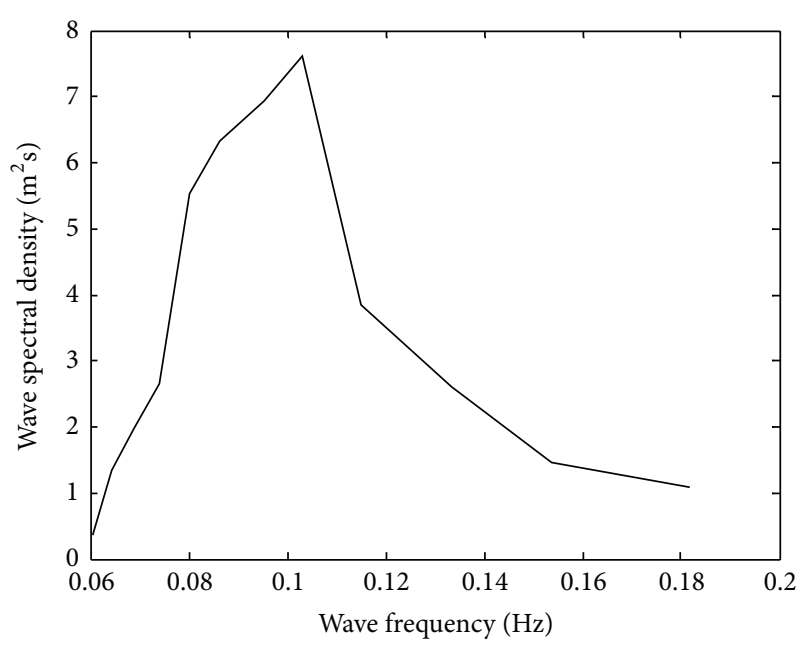

FIGURE 2: Representative spectrum of the wave climate.

Taking these data into consideration, a regular wave may be modelled assuming that its height and frequency correspond to the peak given in Figure 2 so that it can be written as follows:

$$
\begin{gathered}
P_{\mathrm{wf}}=\frac{\rho_{w} g A^{2} \lambda}{16 T_{w}}\left[1+\frac{4 \pi h / \lambda}{\sinh (4 \pi h / \lambda)}\right], \\
\lambda=\frac{g T_{w}^{2}}{2 \pi} \tanh \left(\frac{2 \pi h}{\lambda}\right) .
\end{gathered}
$$

A thorough overview of wave theory and models may be found in [25].

The breakwater housing the OWC plant is located at a depth of $5 \mathrm{~m}$ below MESTLW (Maximum Equinoctial Spring Tide Low Water) with respect to Level 0 at Mutriku port. The opening that transmits the wave oscillations to each air column is $3.20 \mathrm{~m}$ high and $4.00 \mathrm{~m}$ wide. The lowest point is at $-3.40 \mathrm{~m}$, so that the opening is always below sea level [26].

The power available from the air flow in the OWC chamber, which parameters are presented in Figure 3, may be expressed in terms of the air pressure drop and the kinetic energy as follows:

$$
P_{\text {in }}=\left(d p+\frac{\rho v_{x}^{2}}{2}\right) v_{x} a .
$$

For a complete description see [25].

\subsection{Turbo-Generator Module. In the Mutriku OWC, the tur-} bines are fixed-pitch, which means that they present a robust performance due to the lack of air flow rectifying devices, since they always rotate in the same direction regardless of the air flow and are vertically mounted with a butterfly type valve at the bottom to isolate the chamber if necessary. To minimize the height of the plant room, the length of the turbo-generation assembly has been designed to be relatively small: $2.83 \mathrm{~m}$ high by $1.25 \mathrm{~m}$ maximum width and approximately $1200 \mathrm{~kg}$ (see Figures 1 and 4).

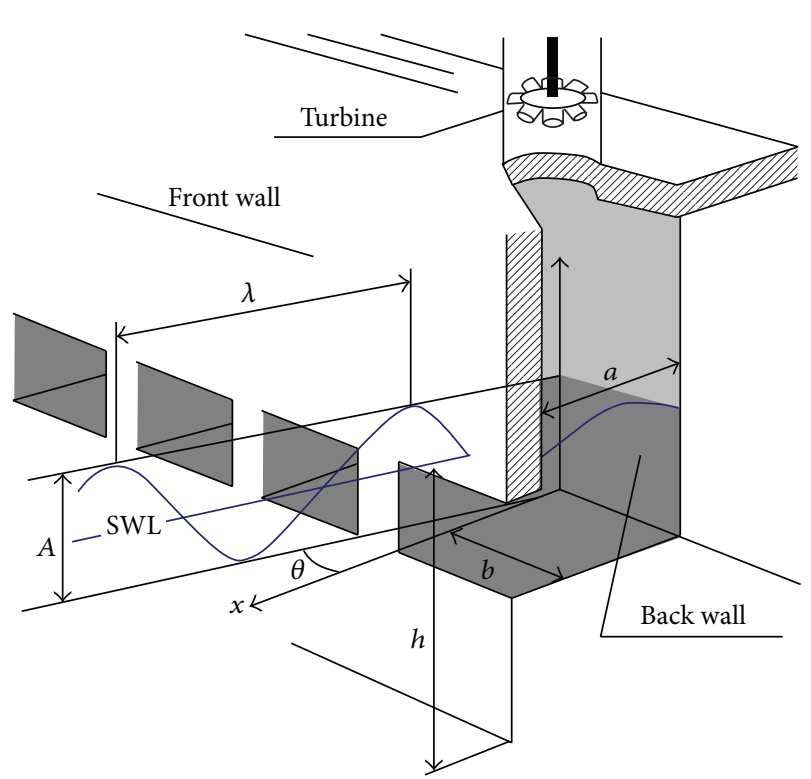

FiguRE 3: OWC capture chamber.

The equations used for modelling the pressure drop across rotor and the torque produced by turbine are (see [27])

$$
\begin{aligned}
d p & =C_{a} K\left(\frac{1}{a}\right)\left[v_{x}^{2}+\left(r \omega_{r}\right)^{2}\right], \\
T_{t} & =C_{t} K r\left[v_{x}^{2}+\left(r \omega_{r}\right)^{2}\right],
\end{aligned}
$$

where $K$ is the turbine constant defined as

$$
K=\frac{\rho b n l}{2}
$$

so that it may be deduced that the torque

$$
T_{t}=\frac{d p C_{t} r a}{C_{a}} .
$$

The flow coefficient, $\phi$, is usually defined as the nondimensional quantity corresponding to the tangent of the angle of attack at the blade tip. The flow coefficient is

$$
\phi=\frac{v_{x}}{r \omega_{r}} .
$$

Finally, the flow rate and turbine performance can be calculated as

$$
\begin{gathered}
q=v_{x} a, \\
\eta_{t}=\frac{T_{t} \omega_{r}}{d p q} .
\end{gathered}
$$

Thus, it may be observed from (3) and (7) that for a given rotational speed, it is possible to establish a linear relationship between the pressure drop and the flow rate. This facilitates an adequate coupling between the turbine and the OWC, which also depends on the pressure drop input. Besides, the developed torque, that is to say the turbine power, depends 


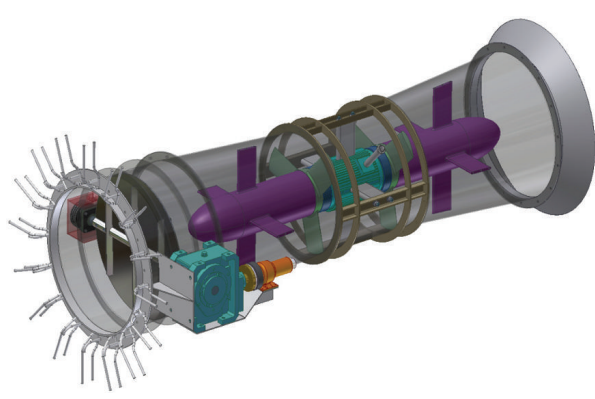

(a)

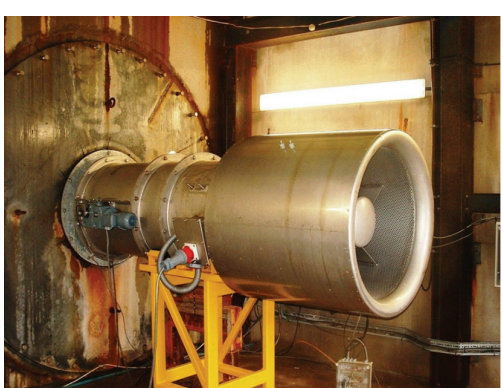

(b)

FIgURE 4: Turbines for the Mutriku OWC project by the EVE.

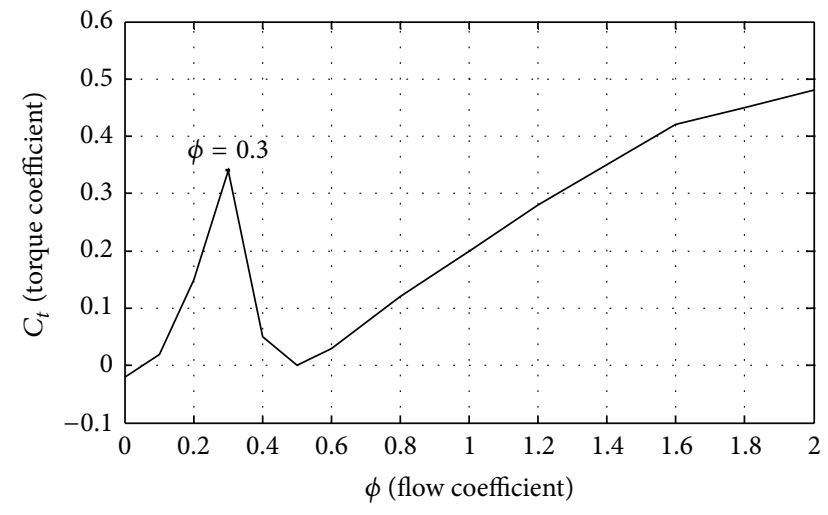

FIGURE 5: Torque coefficient versus flow coefficient from the datasheet turbine specifications.

on the pressure drop, the power coefficient, and the torque coefficient (6). It is the relationship of this torque coefficient against the flow coefficient that determines one of the characteristic curves of the Wells turbine under study. It is particularly interesting the behaviour of the torque coefficient $C_{t}$, shown in Figure 5, since it shows that it is negative during the start-up phase, which means that, due to the properties of the turbine, the AC machine acts as a motor until it overcomes the drag forces acting on the blades. Figure 5 also shows that when the flux coefficient reaches a critical value the torque coefficient will drop drastically, which is commonly known as the stalling behaviour of the Wells turbine. On the other hand, when the turbine velocity increases the flow rate decreases (see (7)). Therefore, accelerating the turbine adequately will avoid that the turbine enters into stalling behaviour, drastically dropping its efficiency.

It may be seen in Figure 6 how the performance of the Wells turbine deteriorates when the flow coefficient approaches the corresponding $C_{t}$ critical value of Figure 5, 0.3. This behaviour is denoted stalling behaviour and it is the reason why control is particularly relevant in Wells turbines.

In this way, this undesired stalling behaviour can be avoided or delayed if the turbine accelerates fast enough in response to the incoming air flow in order to maintain adequate flow coefficient values (7) (see [8]), so as to maintain the optimal flow coefficient for an efficient conversion of pneumatic power.

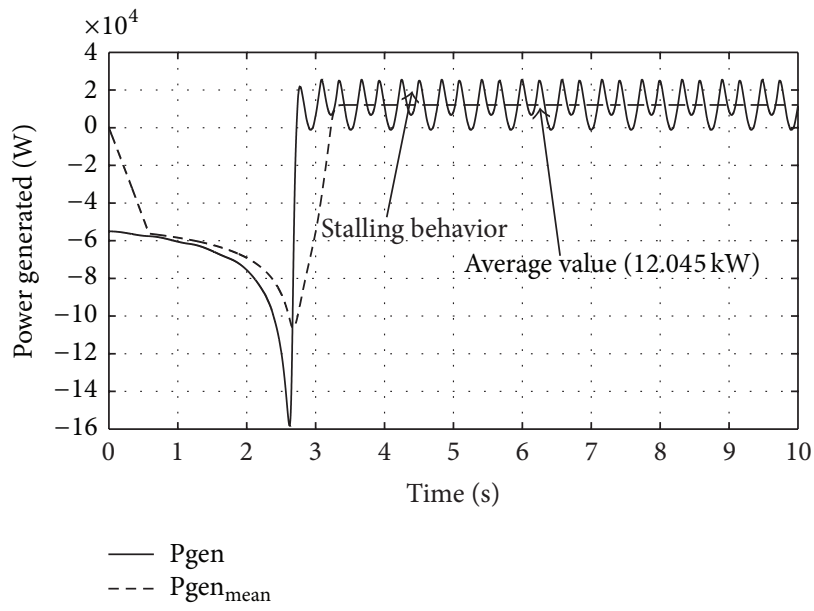

FIGURE 6: Simulated power generated for $7000 \mathrm{~Pa}$ maximum pressure drop input under no control (stalling).

The Mutriku OWC consists of 16 chambers, where each chamber has a top opening that is connected to a vertically mounted turbo-generator module. Each module is formed by two five-blade Wells turbines connected to an air cooled DFIG generator. In this kind of induction machines, widely employed in diverse generation applications, the stator circuit is directly connected to the grid while the rotor windings are connected via slip-rings to a three-phase AC-DC-AC source converter that controls both the rotor and the grid currents, so that the rotor frequency is independent of the grid frequency.

The turbine set has fresh water injectors, which regularly clean the blades of any accumulations of encrusted salt, and on the other hand the turbo-generator control requires a precise knowledge of system parameters and of the rotor speed in particular. Thus, to remove the speed sensor rotor is to simplify the hardware, with the consequent reduction in installation and maintenance costs. A detailed description of the OWC numerical model may be found in [28].

\section{A Sensorless Control Scheme}

In this section, a sensorless control scheme with an observer for the induction rotor speed based on a disturbance model 


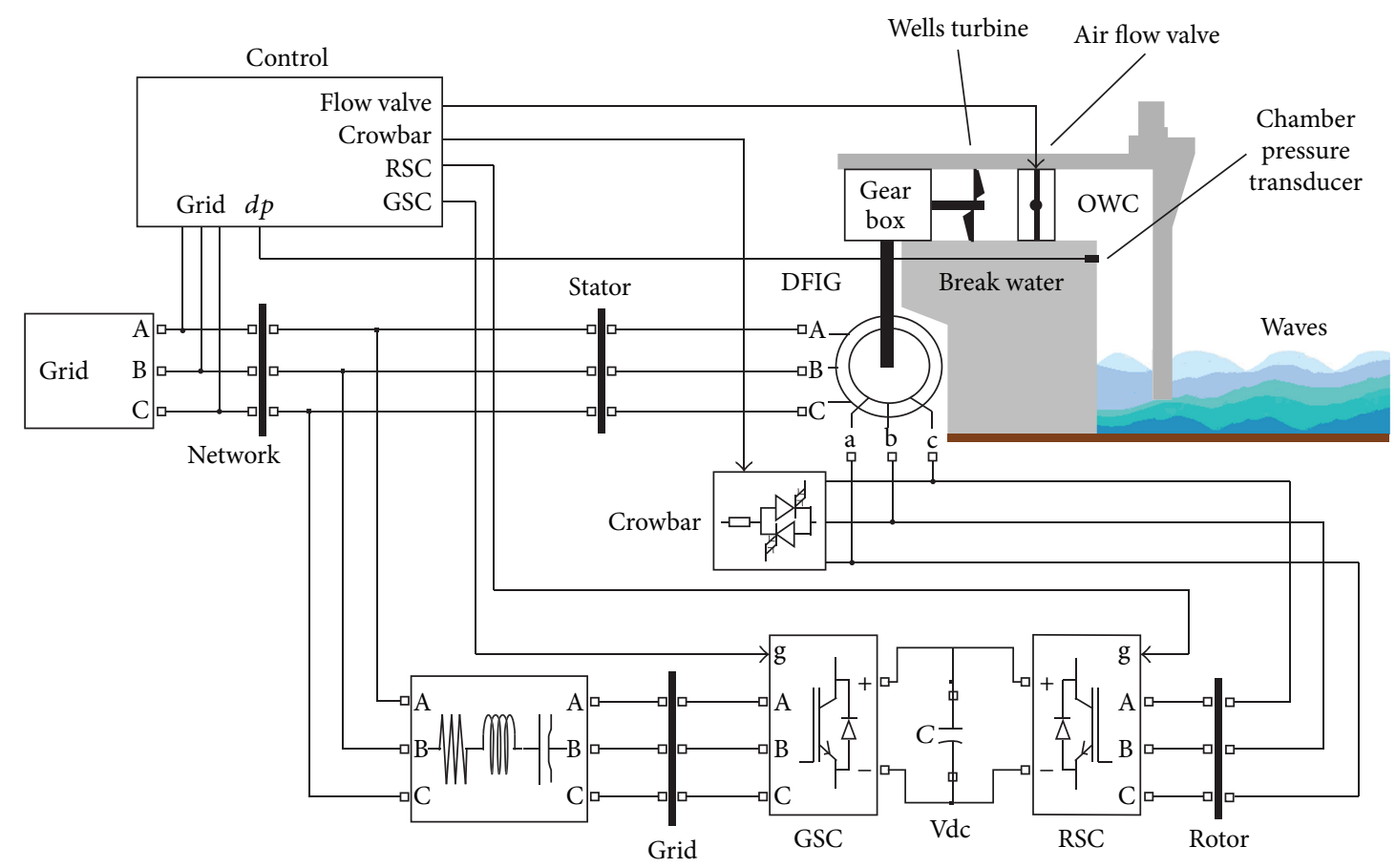

FIgURE 7: OWC control scheme.

is presented. AC drives without speed sensors on the rotor shaft compose a common strategy for cost reduction and robustness, especially in hostile environments (see [29-35]). The proposed observer aims to accurately estimate the rotor angular velocity by employing the stator current and stator voltage as input variables in a closed loop observer structure that was first introduced in [18].

A point tracking technique will be implemented for the control to track a curve that yields the maximum possible power from the sea for any given environmental conditions. This Tracking Characteristic Curve (TCC) is predefined for each turbine, by adjusting the shaft speed of the OWC turbogenerator, so that the flow coefficient $\phi$ remains bounded, yielding a maximum stalling-free torque coefficient $C_{t}$. Therefore, for a given pressure drop input $d p$ there is a unique generator slip and a power reference required to satisfy the conditions of maximum wave energy extraction. In our particular case, this TCC is achieved based on a previous study of the Wells turbine at hand using the characteristic curve provided by the manufacturer (see Figure 5), and the required slip values are shown in Table 1 .

The control scheme is shown in Figure 7 and its design requires taking into account the dynamics of the turbogenerator module. In particular, in the DFIG-based OWC generation system, the maximum power objective is achieved by regulating the current of the rotor in the RSC. In order to achieve independent control of the stator active power, $P$, and reactive power, $Q$, the direct and quadrature components of the rotor currents $i_{q r}, i_{d r}$ are used to provide the required voltage signal $v_{q r}, v_{d r}$ by means of PI controllers. Besides, since the OWC air flow control actuator is a throttle-valve subject to saturation, it was necessary to consider an integral wind-up
TABLE 1: Pressure drop input versus slip reference and corresponding flux coefficient variation.

\begin{tabular}{lcc}
\hline$d P_{\text {AVERAGE }}(\mathrm{Pa})$ & $\operatorname{slip}_{\text {AVER }}(\%)$ & Flow Coef. $\varphi$ \\
\hline $0-5500$ & -0.56 & $0-0.2987$ \\
$5500-5790$ & -2.34 & $0-0.2999$ \\
$5790-5975$ & -4.13 & $0-0.2995$ \\
$5975-6175$ & -6.00 & $0-0.2999$ \\
$6175-6375$ & -7.90 & $0-0.2995$ \\
$6375-6600$ & -9.86 & $0-0.2995$ \\
$6600-6850$ & -11.94 & $0-0.2999$ \\
$6850-7100$ & -14.06 & $0-0.2998$ \\
$7100-7375$ & -16.28 & $0-0.2998$ \\
$7375-7670$ & -18.60 & $0-0.2999$ \\
\hline
\end{tabular}

effect, in order to avoid this undesired phenomenon. The steps for tuning a PID controller via the closed-loop ZieglerNichols method consist of considering all controller gains zero and then increasing the proportional gain $K_{p}$ up to a value $K_{p}=K_{c r}$ where sustained oscillations occur with period $P_{c r}$. Using this procedure, some initial values for the controller parameters were obtained and afterwards refined in an experimental trial-and-error basis. In this way, the obtained throttle valve controller gains are $K_{p}=0.6, T_{i}=0.5$, and $T_{d}=0.125$ for initial $K_{c r}=0.04$ and $P_{c r}=0.008$ values. Then, the output control drives the valve into the demanded position against a counterbalance weight. Once in position, it is hold steady by an electromagnetic brake. In the event of a control failure or in the case that the grid connection is lost or an emergency closure is demanded, the brake supply is interrupted, and the valve closes by means of the influence of 


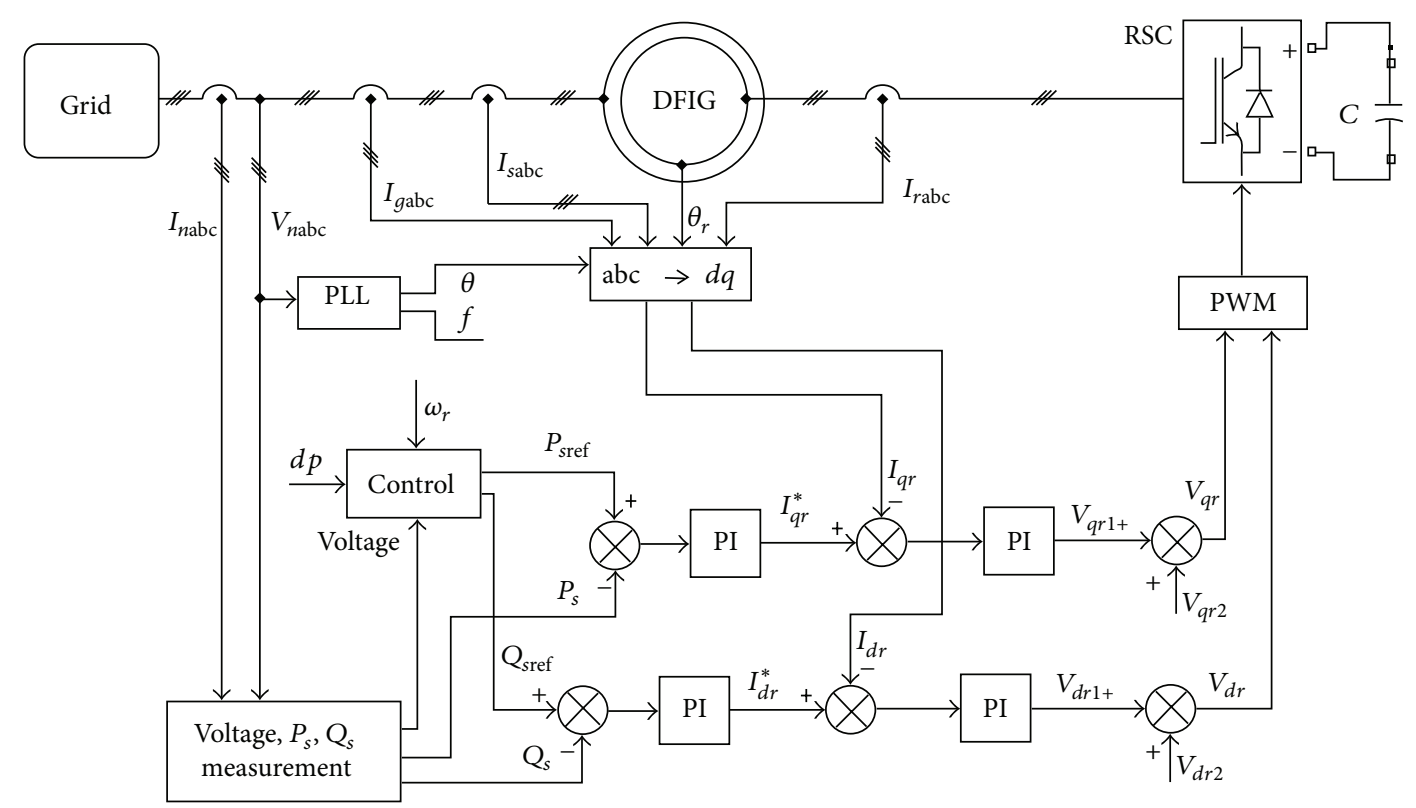

Figure 8: Control loop for the RSC.

the weight. In this way, the modulation of the valve aims to adjust the pressure drop across the turbine rotor.

Thus, the proposed sensorless speed controller actively controls the rotor slip by means of the rotor side converter of the DFIG that acts as control actuator so as to avoid the stalling behaviour and to increase the output power. The functioning of the control scheme is detailed as follows. The DFIG is attached to the Wells turbine by means of a gear box. The DFIG stator windings are connected directly to the grid while the rotor windings are connected to the back to back (AC/DC/AC) converter.

The converter is composed of a GSC connected to the grid and a rotor RSC connected to the wound rotor windings. The RSC controls the active $\left(P_{s}\right)$ and reactive $\left(Q_{s}\right)$ power of the DFIG independently, while the GSC controls the DC voltage and grid side reactive power.

As indicated before, the RSC operates as control actuator and its objective is to regulate the DFIG rotor speed by varying the rotor slip in accordance with the control law signal provided by the rotational speed controller, in such a way that it establishes the maximum power generation allowed at each time instant for the current wave without entering in stalling. In order to achieve this, it is needed an independent regulation of the stator active power (by means of speed control) and reactive power.

The control loop of the RSC is depicted in Figure 8 and the corresponding loop for the GSC would be similar.

This converter controls the active power $\left(P_{s}\right)$ and reactive power $\left(Q_{s}\right)$ of the DFIG. In order to achieve independent control of them, the instantaneous three-phase rotor currents $i_{\text {rabc }}$ are sampled and transformed into $d$-q components $i_{q r}$ and $i_{d r}$ in the stator-flux oriented reference frame. In this context, $P_{s}$ and $Q_{s}$ can be represented as functions of the individual current components. Then, the reference active power is compared with the power losses and compensated by the stator flux estimator to form the reference $q$-current $i_{q r}^{*}$, which is then passed through a standard PI controller. Its output $v_{q r 1}$ is in turn compensated by $v_{q r 2}$ to generate the $q$ voltage signal $v_{q r}$. The RSC reactive power control is also used to maintain a constant stator voltage within the desired range when the DFIG is connected to weak power networks without reactive power compensation. When connected to strong power grids, this control may be set to zero. The reference reactive power is compared with its actual measurement to generate the error signal, which is passed through a PI controller to provide the reference signal $i_{d r}^{*}$. Then, it is compared with its actual signal $i_{d r}$ to generate an error, which is then used to provide the required $q$-voltage signal $v_{d r 1}$ by means of a PI controller. In turn, this voltage is compensated by $v_{d r 2}$ to generate the $d$ voltage signal $v_{d r}$ and used by the PWM module to generate the IGBT gate control signals necessary to drive the RSC converter jointly with the $q$-component signal $v_{q r}$ already obtained.

When a grid fault is detected, the primarily objective of the implemented control is the uninterrupted operation feature of the wave energy plant. For this purpose, the rotor is short-circuited by a crowbar and the RSC is blocked to protect it from the rotor high currents, causing the loss of control of active power and reactive power of the DFIG. In order to control the acceleration of the turbo-generator group, the flow is typically reduced accordingly with the modified power reference, regulating the throttle air valve. When the rotor current and DC-link voltage are low enough, the crowbar is turned off and the RSC is restarted. Meanwhile, the GSC keeps the DC-link capacitor voltage constant and the grid side reactive power controllability of the GSC is useful during the process of voltage reestablishment. After voltage recovery, a second crowbar circuit activation may happen if the rotor 
currents or the DC-link voltage exceed their maximum allowed values. When the voltage and frequency of the network return to steady-state values, the references are modified again, restoring the normal functioning of the system. For a detailed description of the different parts of the control scheme (see [36]), further information about DFIG control devices by means of RSC and GSC may be found in [37-39].

For this purpose, a simple Luenberger based observer for the rotor flux and angular velocity will be proposed. Field oriented decoupling is applied, giving all expressions in the stator-flux reference frame where the $d$-axis is aligned with the stator flux linkage vector $\Psi_{s}$, so that $\Psi_{d s}=\Psi_{s}$ and $\Psi_{q s}=0$. This leads to the following relationships (see [38]):

$$
\begin{aligned}
& \frac{d \hat{i}_{q s}}{d t}=a_{1} \hat{i}_{q s}+a_{2} \widehat{\psi}_{q r}+a_{3} \omega_{r} \widehat{\psi}_{d r}+a_{4} v_{q s}+k_{i}\left(i_{q s}-\hat{i}_{q s}\right), \\
& \frac{d \hat{i}_{d s}}{d t}=a_{1} \hat{i}_{d s}+a_{2} \widehat{\psi}_{d r}-a_{3} \omega_{r} \widehat{\psi}_{q r}+a_{4} v_{d s}+k_{i}\left(i_{d s}-\widehat{i}_{d s}\right), \\
& \frac{d \widehat{\psi}_{q r}}{d \tau}=a_{5} \hat{i}_{q s}+a_{6} \widehat{\psi}_{q r}-\zeta_{d}-k_{2}\left(\widehat{\omega}_{r} \widehat{\psi}_{r d}-\zeta_{d}\right), \\
& \frac{d \widehat{\psi}_{d r}}{d \tau}=a_{5} \widehat{i}_{d s}+a_{6} \widehat{\psi}_{d r}+\zeta_{q}+k_{2}\left(\widehat{\omega}_{r} \widehat{\psi}_{q r}-\zeta_{q}\right),
\end{aligned}
$$

where $\widehat{v}_{d s}, \widehat{v}_{q s}, \hat{i}_{d s}, \widehat{i}_{q s}, \widehat{\psi}_{d s}, \widehat{\psi}_{q s}$ are the estimated components of the stator voltage, current and flux vector of the rotor in the reference frame and

$$
\begin{gathered}
a_{1}=-\frac{R_{s} L_{r}^{2}+R_{r} L_{m}^{2}}{w L_{r}}, \\
a_{2}=\frac{R_{r} L_{m}}{w L_{r}}, \quad a_{3}=\frac{L_{m}}{w}, \\
a_{4}=\frac{L_{r}}{w}, \quad a_{5}=\frac{R_{r} L_{m}}{L_{r}}, \\
a_{4}=-\frac{R_{r}}{L_{r}}, \quad w=L_{s} L_{r}-L_{m}^{2} .
\end{gathered}
$$

The structure of this observer is based on treating as disturbances $\zeta_{q}, \zeta_{d}$ the corresponding vectors $\omega_{r} \widehat{\psi}_{q r}, \omega_{r} \widehat{\psi}_{d r}$ so as to remove the coupling between cocoordinates as follows:

$$
\begin{gathered}
\frac{d \zeta_{q}}{d \tau}=k_{1}\left(i_{d s}-\hat{i}_{d s}\right), \\
\frac{d \zeta_{d}}{d \tau}=-k_{1}\left(i_{q s}-\hat{i}_{q s}\right) .
\end{gathered}
$$

The disturbance vector has the same angular velocity as all other vector components. Both disturbance and flux vectors have the same phase and proportional amplitudes so that the velocity may be estimated as

$$
\widehat{\omega}_{r}=S\left(\sqrt{\frac{\zeta_{q}^{2}+\zeta_{d}^{2}}{\widehat{\psi}_{d r}^{2}+\widehat{\psi}_{q r}^{2}}}\right)+k_{4}\left(V-V_{f}\right),
$$

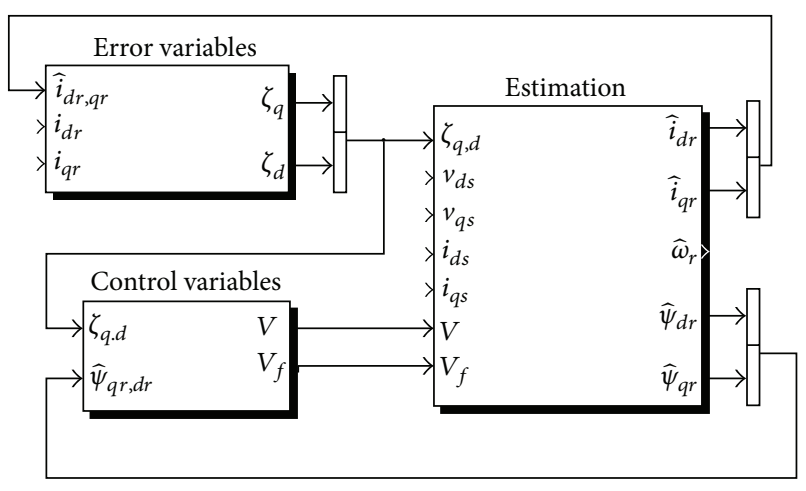

FIGURE 9: Control loop for the state observer.

where $S$ denotes the sign of the angular velocity. The observer gains $k_{1}, k_{4}$ have small values and are selected experimentally while $k_{2}$ depends on the rotor speed

$$
k_{2}=a+b \cdot\left|\widehat{\omega}_{r f}\right|
$$

being $a$ and $b$ constants and $\left|\widehat{\omega}_{r f}\right|$ the absolute value of the estimated filtered rotor speed. $V_{f}$ denotes the filtered signal of the control $V$, which is defined as

$$
V=\widehat{\psi}_{r q} \zeta_{d}-\widehat{\psi}_{r d} \zeta_{q}, \quad \frac{d V_{f}}{d \tau}=\frac{1}{T_{1}}\left(V-V_{f}\right) .
$$

The control loop for this state observer is depicted in Figure 9. A comprehensive description of Luenberger observers may be found in $[40,41]$.

As it has been explained before the stator is connected to the grid, so that the influence of the stator resistance is small and the stator magnetizing current $i_{m s}$ is considered to be constant [42]. For this purpose it is assumed that the machine works away from the magnetic saturation limits. Thus, $T_{e}$ may be defined as

$$
T_{e}=-K_{T} i_{q r}
$$

Therefore, the generator slip may be controlled by regulating the rotor current $i_{q r}$, while the stator reactive power $Q_{s}$

$$
Q_{s}=\frac{3}{2} \frac{-\omega_{s} L_{m}^{2} i_{m s}\left(i_{m s}-i_{d r}\right)}{L_{s}},
$$

may be controlled by regulating the rotor current $i_{d r}$. Consequently, from $T_{e}=-K_{T} i_{q r}$ with $K_{T}=L_{m} i_{m s} / L_{s}$ being a torque constant and taking into account that $P=T \omega$, the sensorless controller that has been designed solves the power tracking problem for DFIG-based OWC power plants in a hostile environment since it allows to achieve maximum power extraction by matching the desired generator slip reference to avoid the stalling behaviour.

\section{Simulation Results}

As it has been indicated, the Nereida OWC demo project [3] includes 16 Wells turbines in a newly constructed rubble 
TABLE 2: System parameters.

\begin{tabular}{lcl}
\hline Turbine & Generator & Converter \\
\hline$n=5(2$ blade rows $)$ & Rated Power $(\mathrm{kW})=18.5$ & DC-Link voltage $(\mathrm{V})=800$ \\
$K=0.5$ & Width $(\mathrm{m})=1.25(\mathrm{t}$-g module $)$ & Pmax $($ p.u. $)=0.4$ \\
$r_{t}=0.375$ & Height $(\mathrm{m})=2.83(\mathrm{t}$-g module $)$ & Rated Current $(\mathrm{A})=12$ \\
$a_{t}=2.3562$ & Pole pairs $=2$ & Max. Transitory Current $(\mathrm{A})=22.8$ \\
Hub/Tip Ratio $=0.43$ & $R_{r}=0.0334$ & Switching Freq. $(\mathrm{kHz})=14.4$ \\
& $R_{s}=0.0181$ & \\
Solidity per row $(\%)=40$ & $L_{l r}=0.16$ & Cut-off Freq. Current Filters $(\mathrm{kHz})=13.2$ \\
Target speed range $(\mathrm{rpm})=1000-3900$ & $L_{l s}=0.13$ & Cut-off Freq. Grid Voltage Filter $(\mathrm{kHz})=1.32$ \\
Tip Mach no $=0.15-0.47$ & $L_{m}=7.413$ & \\
\hline
\end{tabular}

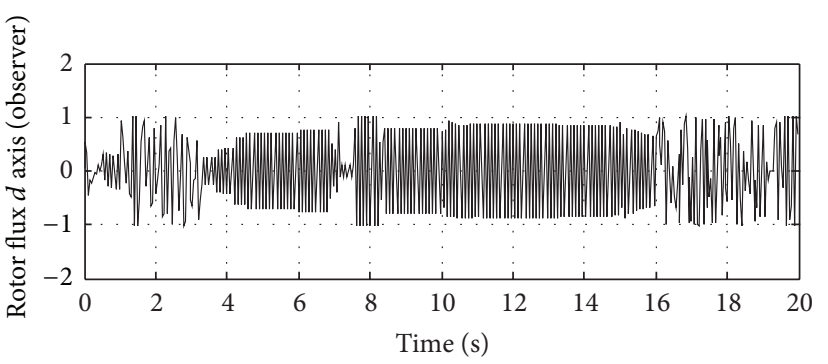

(a)

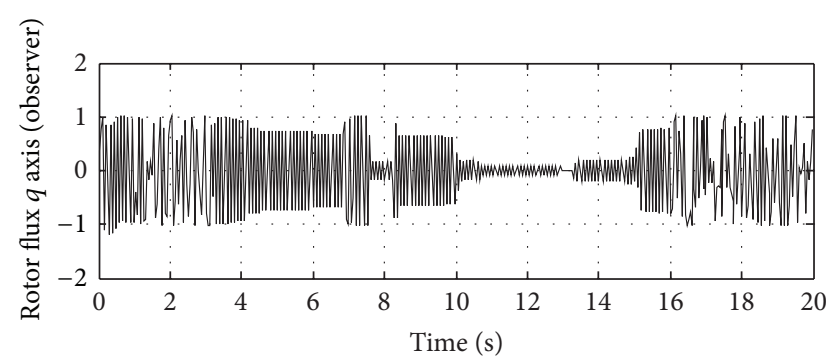

(b)

FIGURE 10: Rotor flux for 7000 Pa maximum pressure drop input (observer).

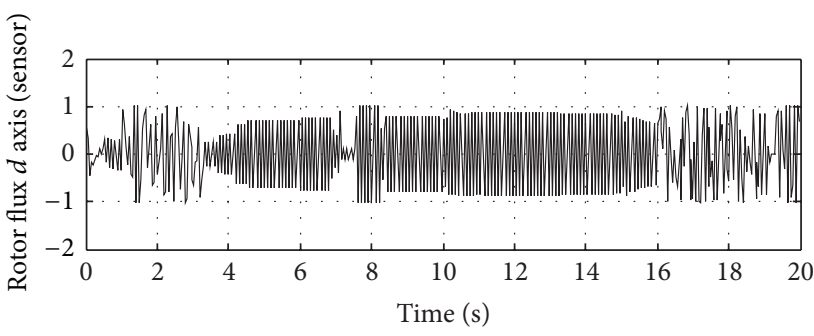

(a)

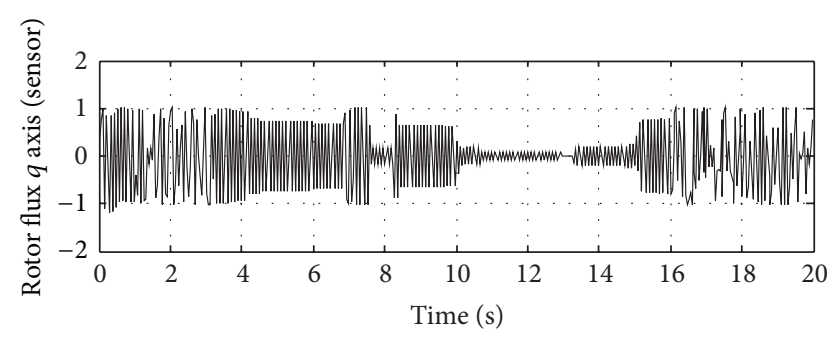

(b)

FIgURE 11: Rotor flux for 7000 Pa maximum pressure drop input (sensor).

mound breakwater in the Basque location of Mutriku, in the northern coast of Spain. The main objective of this section is to demonstrate the viability of the proposed rotor angular velocity observer to help develop this OWC technology with Wells turbine power take-off for future commercial plants. For this reason, the simulation data and wave model have been chosen taking into account the spectrum of the wave climate of Mutriku and the OWC system parameters are listed in Table 2.

For this purpose, the maximum power tracking performance of system subject to the proposed speed estimator with stator current based feedback has been tested by means of numerical simulations. The control strategy is composed of a double feed induction generator, DFIG, that is controlled with a vector field oriented strategy, a crowbar, and an air flow control. The crowbar protects the RSC, enforcing shortcircuit when overcurrents in the rotor occur while the air valve regulates the incoming air flow so as to avoid stalling.
Finally, the main control loop regulates both active and reactive power of the DFIG using the currents as control variables to match the modified power reference (see Figure 7). See [36] for a detailed explanation of this control and [43] for a summary on fault tolerance control.

4.1. Balance Faults. This sensorless control has been applied considering a scenario where waves produce a typical variation for $7000 \mathrm{~Pa}$ maximum pressure drop input and a balanced grid fault has been implemented with an $85 \%$ reduction of the grid voltage applied at $10 \mathrm{~s}$ and cleared at $15 \mathrm{~s}$. For comparison purposes, the same study case has been considered with and without sensor. In particular, in Figure 10 the rotor flux obtained with the proposed sensorless controller is plotted so as to compare it with that obtained using a control where the velocity is computed via a traditional sensor, plotted in Figure 11. As it may be observed there exists no significant difference between them. 


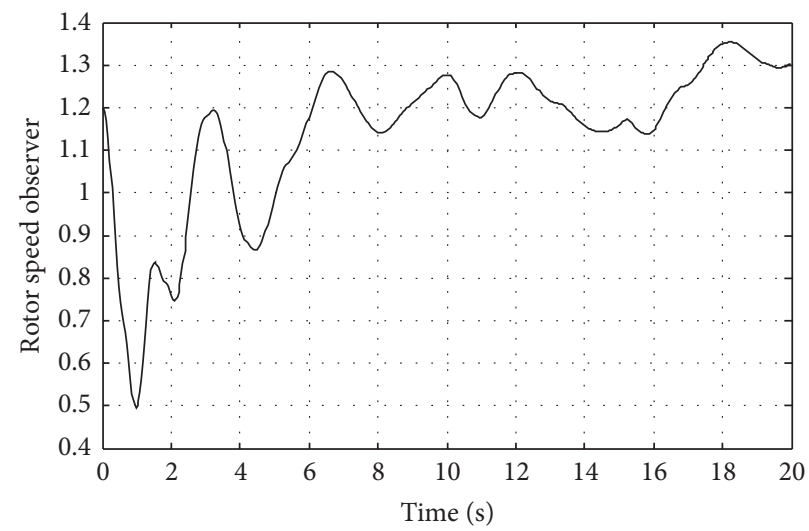

FIGURE 12: Rotor angular velocity for 7000 Pa maximum pressure drop input (observer).
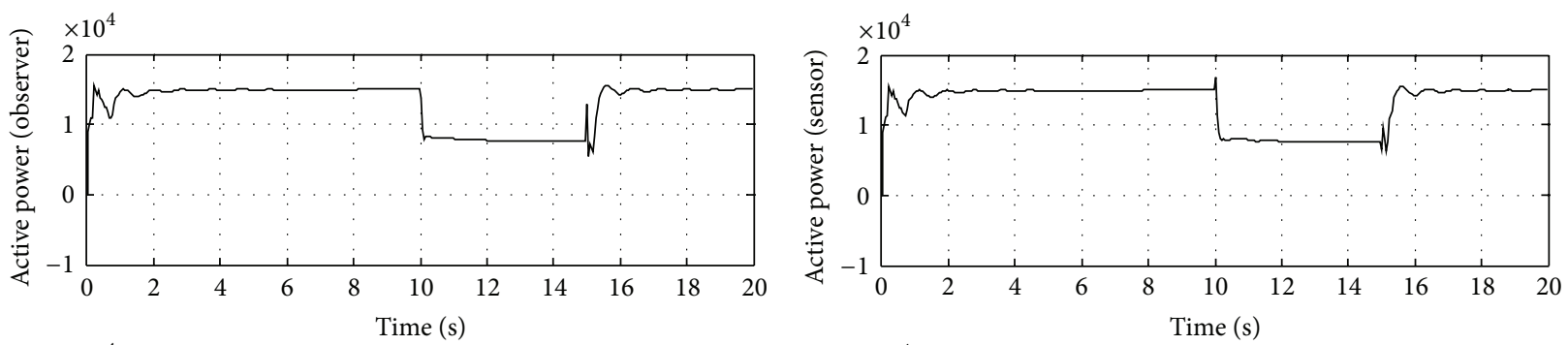

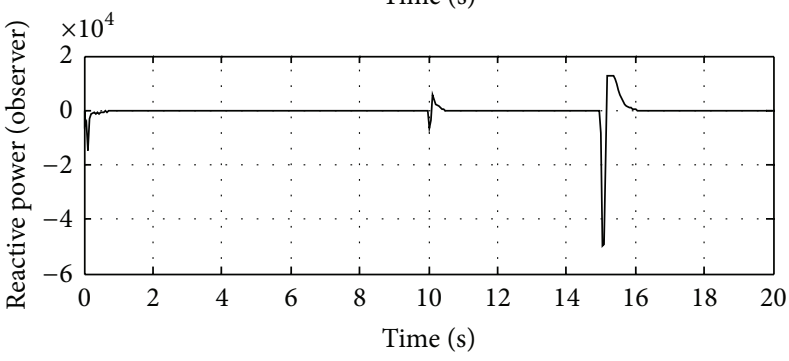

(a)

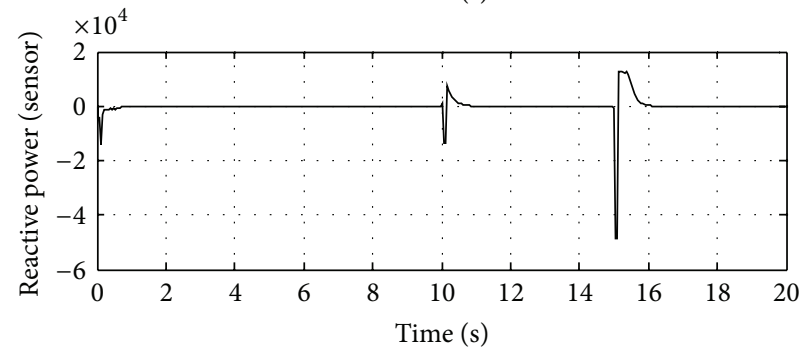

(b)

Figure 13: Active and reactive power generated using sensorless control (a) versus traditional control (b).

Similarly, due to the FRT capability of the control scheme, it may be seen in Figure 12 that after the transitory, $\omega_{r}$ does not increase during the voltage dip, which also affects the flux value. Besides, it should be highlighted that in the Mutriku WOC technical solution, the given reference is the pressure drop whilst the reference for the rotor angular velocity, $\omega_{r}^{*}$, is not readily accessible, so that the proposed estimator with stator current based feedback suits perfectly the requirements of the system.

Analogously, a comparative study for the power generated has been carried out in order to verify the performance of the proposed observer so as to obtain maximum power extraction capability in the plant, even when it is subject to voltage dips like the one described in the scenario at hand.

Under these conditions it may be seen in Figure 13 the effect of the fault over the active and reactive power at the stator terminals both with sensor and with the proposed observer. In both cases, there is no active power consumption during the fault period and the reactive power overshoot during both the start and clearance of the fault is acceptable.
Besides, the generator oscillatory dynamics have been controlled, while giving reactive power to the grid so that it contributes to the attenuation of the voltage dip. In this context, both figures show that the plant generates active and reactive power during the fault period and, particularly, during the fault recovery, since it is only during $100 \mathrm{~ms}$ after the fault recovery that the generator absorbs a little amount of power (less than $60 \%$ of the nominal power). These voltage dips are usually caused by remote grid faults in the power system and would normally require disconnecting the generator from the grid until the faults are cleared. However, normative relative to this requirement tends to enforce maintaining active power delivery and reactive power support to the grid, so that grid codes now require ride through voltage dips like the one presented in this paper.

In order to compare the simulation results obtained using the proposed observer with those obtained using a traditional sensor with the controller, a performance evolution function $J$ is used. This performance function is defined by (16) in terms of the tracking error, where $e(\tau)$ represents the error 


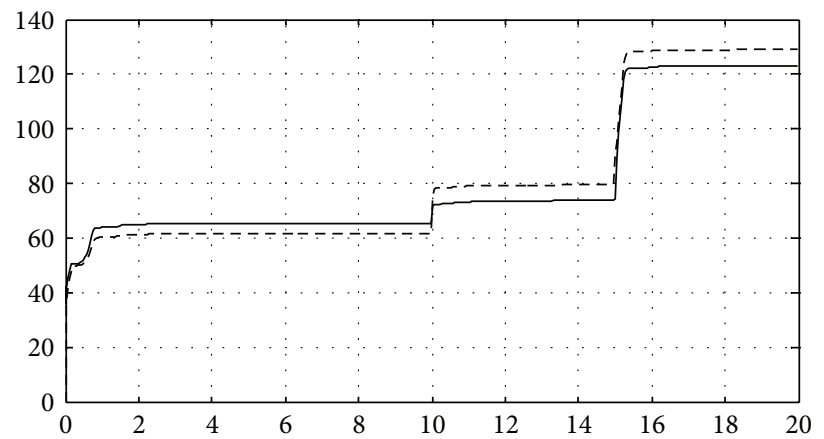

FIGURE 14: Active power performance. Traditional control (-) versus sensorless control (- -).
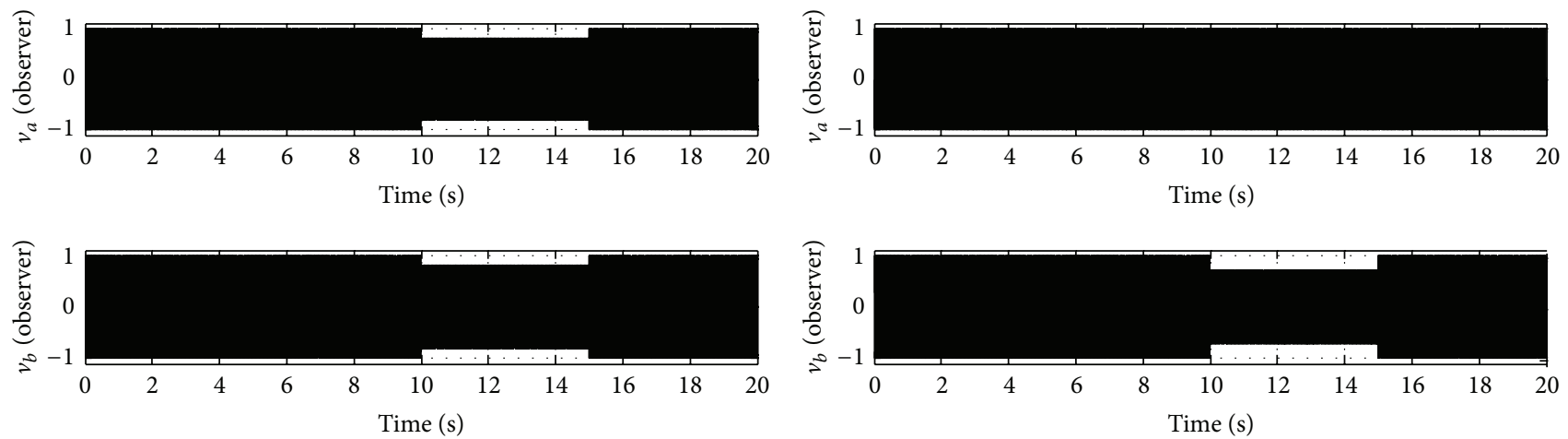

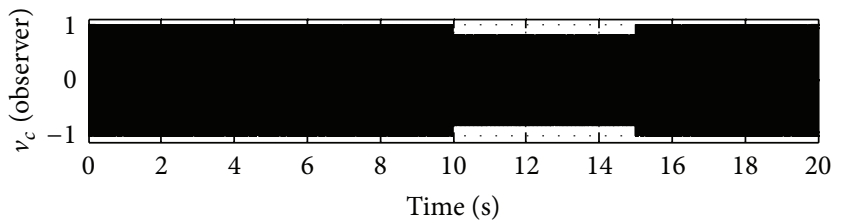

(a)

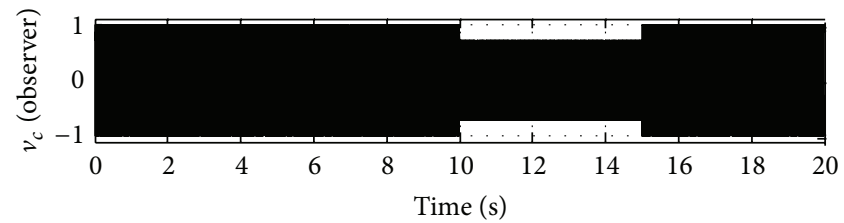

(b)

FIGURE 15: Voltages for the balance fault (a) versus negative sequence unbalance fault (b).
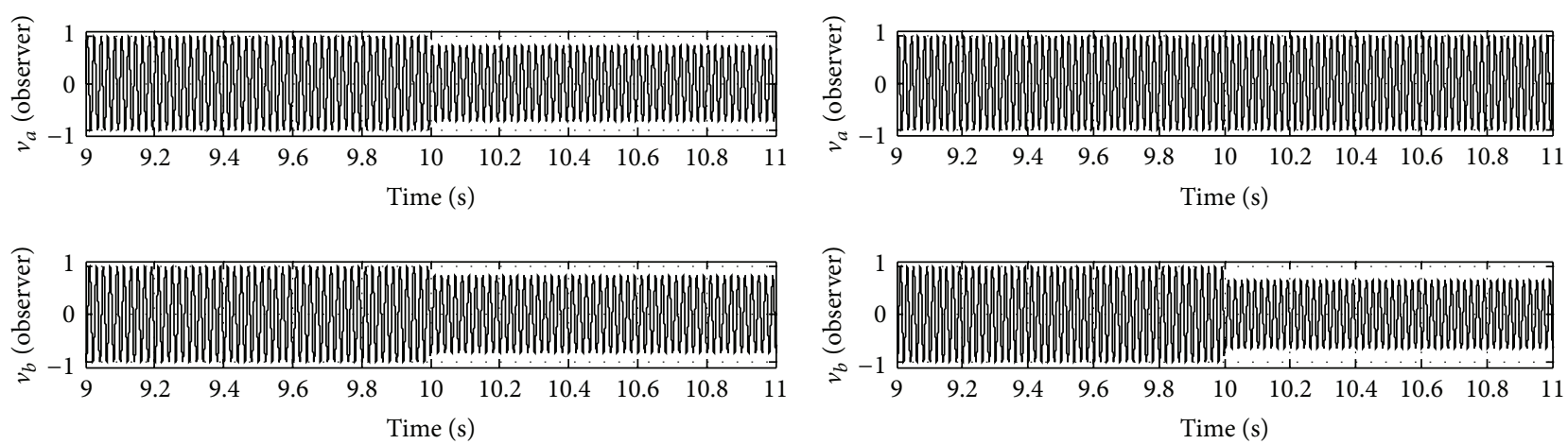

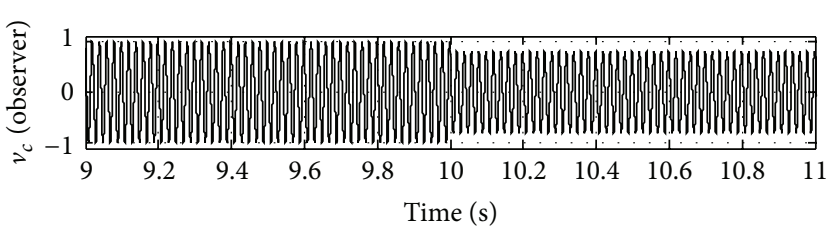

(a)

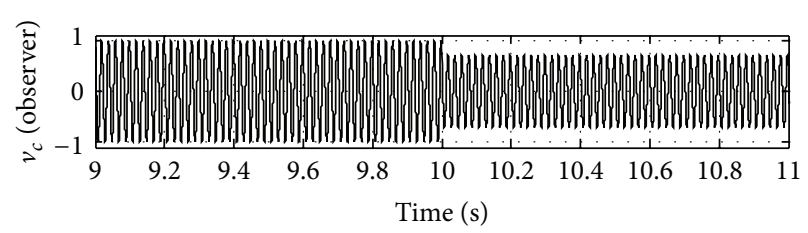

(b)

FIGURE 16: Detail of the voltages for the balance fault (a) versus unbalance fault (b). 


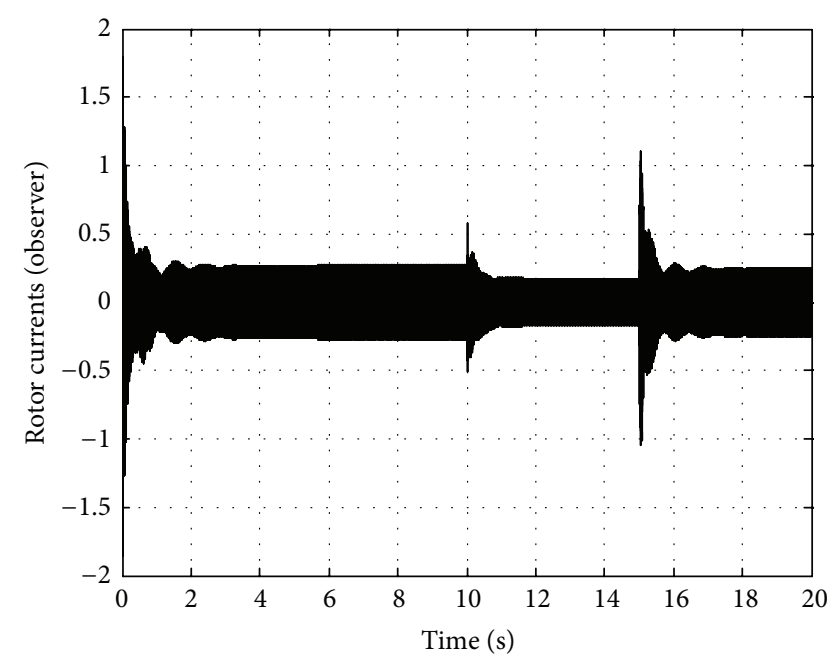

(a)

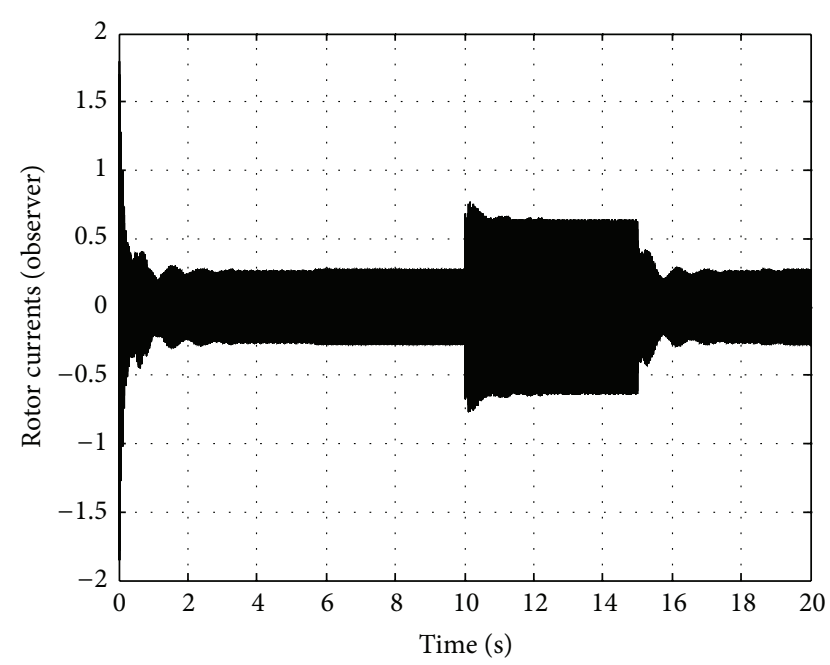

(b)

FIGURE 17: Rotor currents for the balance fault (a) versus negative sequence unbalance fault (b).

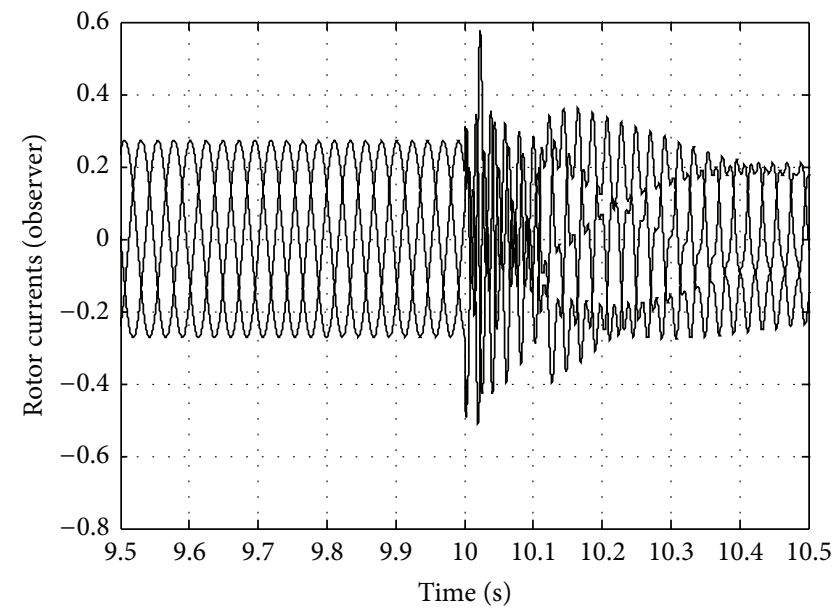

(a)

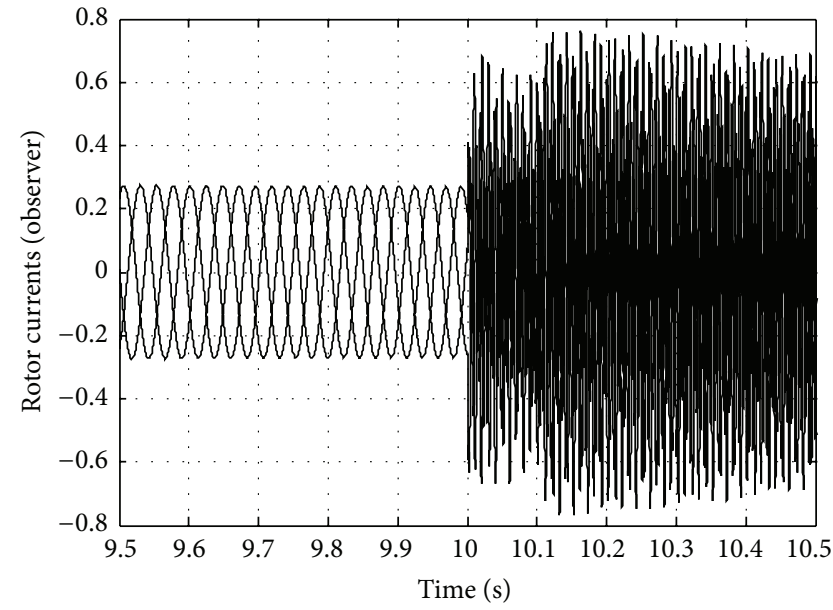

(b)

FIGURE 18: Detail of the rotor currents for the balance fault (a) versus unbalance fault (b).

between the desired reference value for the active power and the value obtained from the system output as follows:

$$
J(t)=\int e^{2}(\tau) d \tau
$$

It can be observed in Figure 14 that the values of the performance evolution function for the case of the controller with observer are slightly higher than those obtained with the sensor. It must be taken into account that the control either with sensor or with observer yields similar results, so that the relevance of the results relies on determining the rotor angular velocity without the need of extra hardware from sensors, just observed by means of the stator voltages and currents. For this reason, although in all cases the accumulated error measured with the cost function $J$ presents a similar increasing behavior, as it should be expected from the $L_{2}$-norm accumulative error defined in (17), it should be noticed that the system power generated in both cases present a similar rate while the observer provides better performance since it increases power extraction in the sense that the plant is more reliable and independent of external disturbances, which is even more relevant in a hostile environment as the ocean.

4.2. Unbalance Faults. Simulation studies on the sensorless control for unbalance faults are carried out over a modification of the balance fault scenario studied in the last section, where a representative example corresponding to the negative sequence is considered as seen in Figures 15 and 16. Previous analyses were performed to confirm the relative significance of the different frequency components present in the current waveforms, corroborating that the negative sequence imposes the most stringent control.

The key problems in the response of a DFIG to an unbalanced fault are illustrated in Figure 17, which shows the rotor 


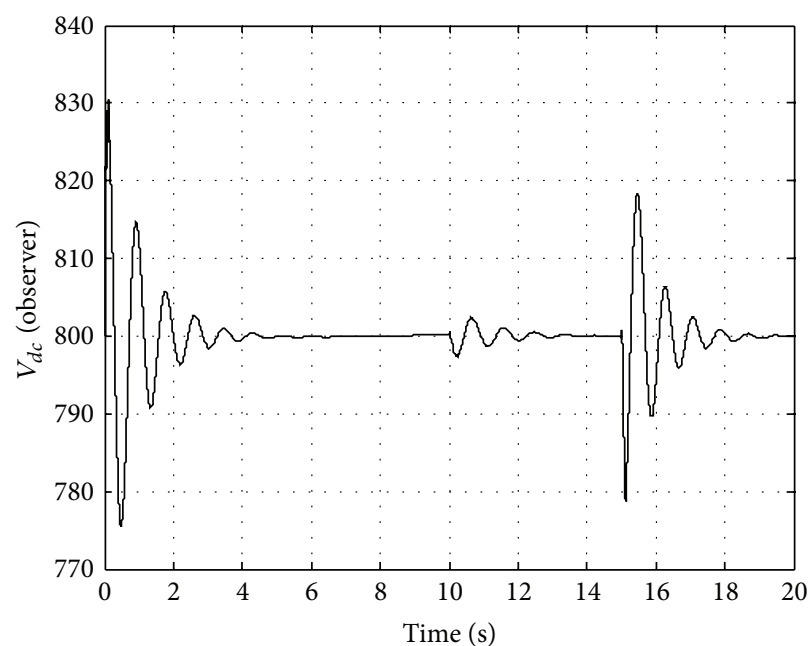

(a)

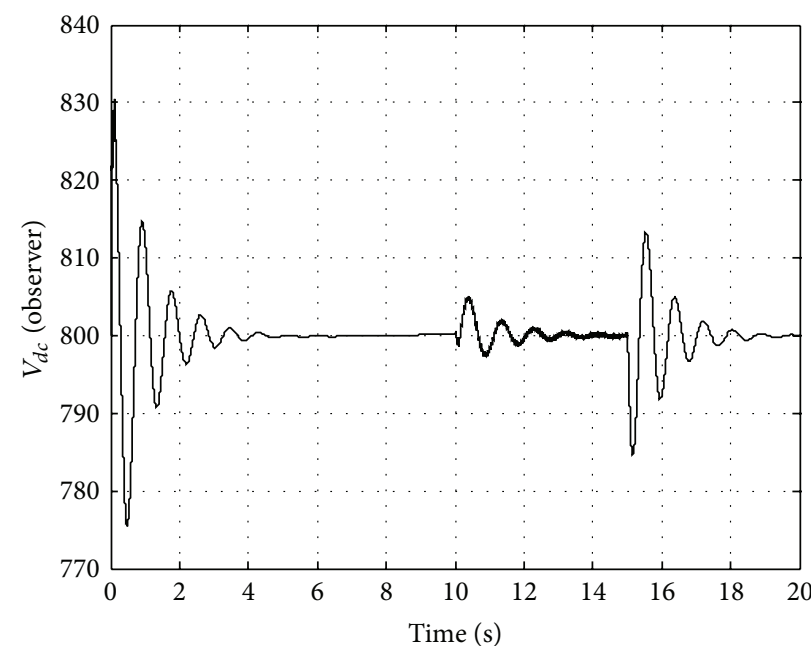

(b)

FIGURE 19: DC-link voltage for the balance fault (a) versus negative sequence unbalance fault (b).
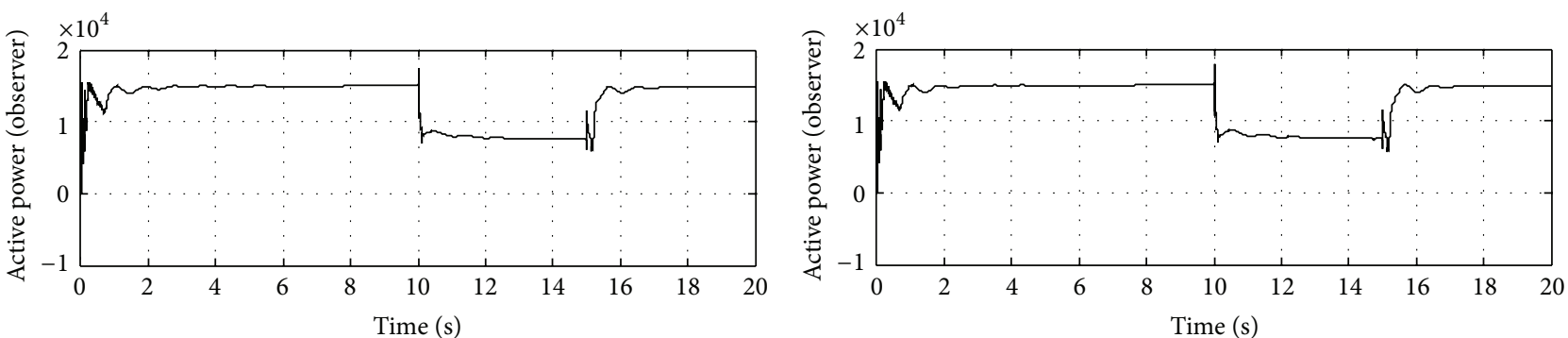

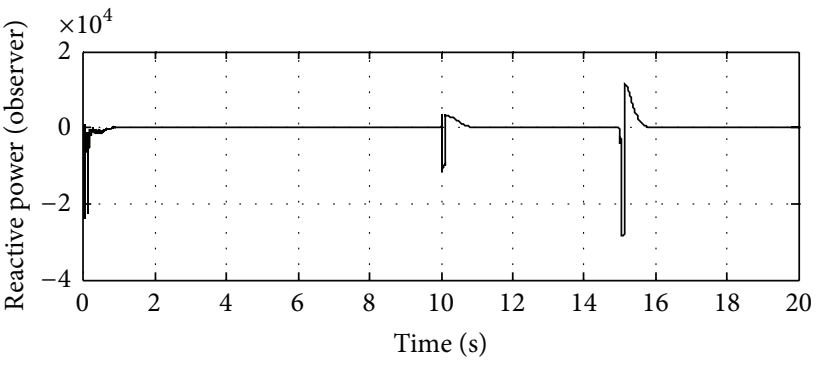

(a)

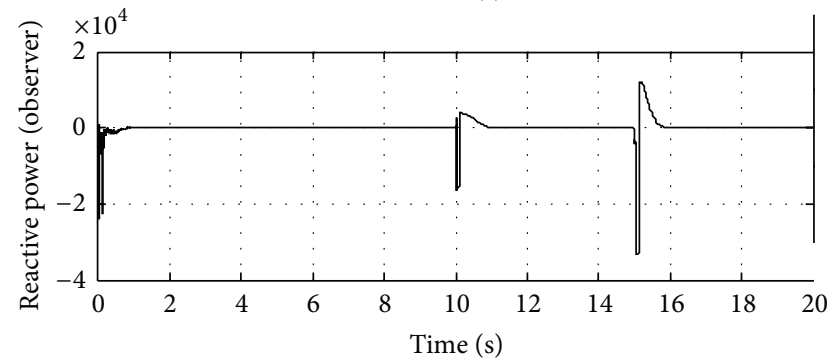

(b)

FIGURE 20: Active and reactive power generated using sensorless control (a) versus traditional sensor (b) considering the negative sequence unbalance fault study case.

currents. During the fault, the negative sequence component of the rotor currents is 2.5 times as large as the positive sequence component. This forces the rotor voltage demand close to the limits of the inverter, making control of the DFIG much more difficult. It can be seen from Figures 17 and 18 that the most serious problem is the rotor overcurrent at fault initiation. These overcurrents are alleviated by shortcircuiting the rotor windings for a short period (known as a crowbar), removing the power electronics from the rotor circuit to protect them from the high currents.

Despite the value of the currents on the IGBTs, it may be seen in Figures 19 and 20 that both the active and reactive power supplies as well as the dc-link voltage are successfully controlled. Thus, even when this control scheme does not discern in the treatment of the different sequence current components during faults, it ensures the continuity of supply in compliance with actual requirements [44].

Although stator overcurrents may also occur, they are generally of less concern, because no vulnerable power electronics are involved in the stator connection.

The results obtained for the reference tests, both with observer and with sensor, confirmed that the model behaved as expected, since there are no obvious differences between them. The effect of the unbalance fault over the active 
and reactive power at the stator terminals may be seen in Figure 20 for comparison purposes.

\section{Conclusions}

This paper has proposed a new observer to estimate the rotor angular speed for the control of the Mutriku OWC wave power generation demo plant within the Nereida project from the Basque Energy Board (EVE). This closed loop observer is based in a Luenberger system and estimates both rotor angular velocity and fluxes using the measured stator voltages and currents. Due to the nature of this observer, the rotor angular velocity is computed from its flux and a vector of cross-product state variables that is treated as disturbances. In order to verify the performance of the proposed observer to obtain maximum power extraction capability in the plant even when it is subject to voltage dips, a comparative study for the power generated with a traditional sensor and with the proposed observer has been performed. A point tracking technique has been implemented so that the control system tracks a curve that yields the maximum possible power from the sea and no substantial differences between them have been found. As a result, it can be concluded that the proposed observer scheme improves the plant reliability by increasing reliability and disturbance rejection while reducing cost and, therefore, improving the power extraction when applied for maximum power generation purposes.

\section{Nomenclature}

$P_{\mathrm{wf}}, P_{\text {in }}$ : Incident wave power, power available to turbine

$g, v, i$ : Gravitationalconstant, voltage, current

$v_{x}, d p$ : Air flow speed, pressure-drop across rotor

$\rho, \rho_{w}: \quad$ Air density, seawater density.

$a, r, n$ : Area of turbine duct, mean radius of the turbine, number of blades

$b, l$ : $\quad$ Blade height, blade chord length

$q, \phi: \quad$ Flow rate, flow coefficient

$\lambda, T_{w}: \quad$ Wavelength, wave period

$h, A$ : Water depth, wave height

$\omega_{r}, T_{t}$ : Angular velocity, torque

$C_{a}, C_{t}$ : Power and torque coefficients

$L, R, \Psi$ : Inductance, resistance, flux

$P, Q: \quad$ Active and reactive power.

\section{Subscripts}

$d, q, s, r:$ Direct and quadrature components, stator and rotor side

$t, g, e, m$ : Turbine, generator, electrical, magnetizing.

\section{Acknowledgments}

This work was supported in part by University of the Basque Country (UPV/EHU) through Research Project GIU11/02 and the Research and Training Unit UFI11/07, by the Ministry of Science and Innovation (MICINN) with Research Project ENE2010-18345, and by the EU FP7 EFDA under the task
WP09-DIA-02-01 WP III-2-c. The authors would also like to thank the collaboration of the Basque Energy Board (EVE) through Agreement UPV/EHUEVE23/6/2011 and the Spanish National Fusion Laboratory (CIEMAT) UPV/EHUCIEMAT08/190.

\section{References}

[1] M. Z. Jacobson and M. A. Delucchi, "Providing all global energy with wind, water, and solar power, part I: technologies, energy resources, quantities and areas of infrastructure, and materials," Energy Policy, vol. 39, no. 3, pp. 1154-1169, 2011.

[2] M. Z. Jacobson and M. A. Delucchi, "Providing all global energy with wind, water, and solar power, part I: technologies, energy resources, quantities and areas of infrastructure, and materials," Energy Policy, vol. 39, no. 3, pp. 1154-1169, 2011.

[3] Basque Energy Board (EVE), http://www.eve.es/Promocionde-inversiones/Proyectos-en-desarrollo/Mutriku/Instalaciones.aspx.

[4] Y. Torre-Enciso, Mutriku Wave Power Plant: From Conception to Reality, European Federation of Regional Energy and Environment Agencies (FEDARENE), 2009, http://www.fedarene.org/ documents/projects/Nereida/Document/01_Mutriku-OWC plant.pdf.

[5] A. Thakker and R. Abdulhadi, "Effect of blade profile on the performance of wells turbine under unidirectional sinusoidal and real sea flow conditions," International Journal of Rotating Machinery, vol. 2007, Article ID 51598, 8 pages, 2007.

[6] T. Setoguchi and M. Takao, "Current status of self rectifying air turbines for wave energy conversion," Energy Conversion and Management, vol. 47, no. 15-16, pp. 2382-2396, 2006.

[7] W. Qiao, G. K. Venayagamoorthy, and R. G. Harley, "Real-time implementation of a STATCOM on a wind farm equipped with doubly fed induction generators," IEEE Transactions on Industry Applications, vol. 45, no. 1, pp. 98-107, 2009.

[8] M. Amundarain, M. Alberdi, A. J. Garrido, and I. Garrido, "Modeling and simulation of wave energy generation plants: output power control," IEEE Transactions on Industrial Electronics, vol. 58, no. 1, pp. 105-117, 2011.

[9] Y. Zhou, J. Lian, T. Ma, and W. Wang, "Design for motor controller in hybrid electric vehicle based on vector frequency conversion technology," Mathematical Problems in Engineering, vol. 2010, Article ID 627836, 21 pages, 2010.

[10] K. J. Astrom and T. Hagglund, Advanced PID Control, ISA-The Instrumentation, Systems, and Automation Society, 2009.

[11] R. Vilanova, V. M. Alfaro, O. Arrieta, and C. Pedret, "Analysis of the claimed robustness for PI/PID robust tuning rules," in Proceedings of the 18th Mediterranean Conference on Control and Automation (MED '10), pp. 658-662, June 2010.

[12] B. C. Rabelo Jr., W. Hofmann, J. L. da Silva, R. G. de Oliveira, and S. R. Silva, "Reactive power control design in doubly fed induction generators for wind turbines," IEEE Transactions on Industrial Electronics, vol. 56, no. 10, pp. 4154-4162, 2009.

[13] ESB National Grid, "Discussion Document for the Review of Requirements for Wind Turbine Generators Under System Fault Conditions," 2003.

[14] I. Serban, F. Blaabjerg, I. Boldea, and Z. Chen, A Study of Doubly Fed Wind Power Generator Under Power System Faults, EPE, Toulouse, France, 2003.

[15] G. Iwanski and W. Koczara, "DFIG-based power generation system with UPS function for variable-speed applications," IEEE 
Transactions on Industrial Electronics, vol. 55, no. 8, pp. 30473054, 2008

[16] G. Abad, M. Á. Rodríguez, G. Iwanski, and J. Poza, "Direct power control of doubly-fed-induction-generator-based wind turbines under unbalanced grid voltage," IEEE Transactions on Power Electronics, vol. 25, no. 2, pp. 442-452, 2010.

[17] A. J. Garrido, I. Garrido, M. Amundarain, and M. Alberdi, "Sliding-mode control of wave power generation plants," IEEE Transactions on Industry Applications, vol. 48, no. 6, pp. 23722381, 2012.

[18] Z. Krzeminski, "New speed observer for control system of induction motor," in Proceedings of the 3rd IEEE International Conference on Power Electronics and Drive Systems (PEDS '99), pp. 555-560, July 1999.

[19] Z. Krzemiński, "Observer of induction motor speed based on exact disturbance model," in Proceedings of the 13th International Power Electronics and Motion Control Conference (EPEPEMC '08), pp. 2294-2299, September 2008.

[20] O. Barambones, P. Alkorta, A. J. Garrido, I. Garrido, and F. J. Maseda, "An adaptive sliding mode control scheme for induction motor drives," International Journal of Circuits, Systems and Signal Processing, vol. 1, no. 1, pp. 73-78, 2007.

[21] O. Barambones and A. J. Garrido, "An adaptive variable structure control law for sensorless induction motors," European Journal of Control, vol. 13, no. 4, pp. 282-392, 2007.

[22] J. C. Garcia, C. Diego, P. F. de Arróyabe, C. Garmendia, and D. Rasilla, El Clima Entre el Mar y la Montaña, The University of Cantabria, Santander, Spain, 2004.

[23] I. Galparsoro et al., "atlas de energía dek oleaje en la costa Vasca. La planificación espacial marian como herramienta en la selección de zonas adecuadas para la instalacion de captadores," in Revista De Investigación Marina, pp. 1-9, 2008.

[24] W. K. Tease, J. Lees, and A. Hall, "Advances in oscillating water column air turbine development," in Proceedings of the 7th European Wave and Tidal Energy Conference, Porto, Portugal, 2007.

[25] M. Alberdi, M. Amundarain, A. J. Garrido, I. Garrido, O. Casquero, and M. De La Sen, "Complementary control of oscillating water column-based wave energy conversion plants to improve the instantaneous power output," IEEE Transactions on Energy Conversion, vol. 26, no. 4, pp. 1021-1032, 2011.

[26] Y. Torre-Enciso, I. Ortubia, L. I. López de Aguileta, and J. Marqués, "Mutriku wave power plant: from the thinking out to the reality," in Proceedings of the 8th European Wave and Tidal Energy Conference, pp. 319-329, 2009.

[27] A. El Marjani, F. Castro Ruiz, M. A. Rodriguez, and M. T. Parra Santos, "Numerical modelling in wave energy conversion systems," Energy, vol. 33, no. 8, pp. 1246-1253, 2008.

[28] M. Amundarain, M. Alberdi, A. J. Garrido, I. Garrido, and J. Maseda, "Wave energy plants: control strategies for avoiding the stalling behaviour in the Wells turbine," Renewable Energy, vol. 35, no. 12, pp. 2639-2648, 2010.

[29] P. Guglielmi, R. Bojoi, G. Pellegrino, A. Cavagnino, M. Pastorelli, and A. Boglietti, "High speed sensorless control for induction machines in vacuum pump application," in Proceedings of the 37th Annual Conference of the IEEE Industrial Electronics Society (IECON '11), pp. 1872-1878, November 2011.

[30] R. Cárdenas, R. Peña, G. Asher, J. Clare, and J. Cartes, "MRAS observer for doubly fed induction machines," IEEE Transactions on Energy Conversion, vol. 19, no. 2, pp. 467-468, 2004.
[31] R. Cárdenas, R. Peña, J. Clare, G. Asher, and J. Proboste, "MRAS observers for sensorless control of doubly-fed induction generators," IEEE Transactions on Power Electronics, vol. 23, no. 3, pp. 1075-1084, 2008.

[32] S. Mueller, M. Deicke, and R. W. De Doncker, "Adjustable speed generators for wind turbines based on doubly-fed induction machines and 4-quadrant IGBT converters linked to the rotor," in Proceedings of the 35th IAS Annual Meeting and World Conference on Industrial Applications of Electrical Energy, vol. 4, pp. 2249-2254, October 2000.

[33] L. Morel, H. Godfroid, A. Mirzaian, and J. M. Kauffmann, "Double-fed induction machine: converter optimisation and field oriented control without position sensor," IEE Proceedings of Electric Power Applications, vol. 145, no. 4, pp. 360-368, 1998.

[34] H. R. Karimi and M. Chadli, "Robust observer design for Takagi-Sugeno fuzzy systems with mixed neutral and discrete delays and unknown inputs," Mathematical Problems in Engineering, vol. 2012, Article ID 635709, 13 pages, 2012.

[35] S. Chen, Y. F. Li, J. Zhang, and W. Wang, Active Sensor Planning for Multiview Vision Tasks, Springer, 2008.

[36] M. Alberdi, M. Amundarain, A. J. Garrido, I. Garrido, and F. J. Maseda, "Fault-ride-through capability of oscillating-watercolumn-based wave-power-generation plants equipped with doubly fed induction generator and airflow control," IEEE Transactions on Industrial Electronics, vol. 58, no. 5, pp. 15011517, 2011.

[37] R. Pena, J. C. Clare, and G. M. Asher, "A doubly fed induction generator using back-to-back PWM converters supplying an isolated load from a variable speed wind turbine," IEE Proceedings on Electric Power Applications, vol. 143, no. 3, pp. 231-241, 1996.

[38] B. K. Bose, Modern Power Electronics and AC Drives, PrenticeHall, Englewood Cliffs, NJ, USA, 2001.

[39] I. Sarasola, J. Poza, M. A. Rodriguez, and G. Abad, "Direct torque control design and experimental evaluation for the brushless doubly fed machine," Energy Conversion and Management, vol. 52, no. 2, pp. 1226-1234, 2011.

[40] A. Lagrioui and H. Mahmoudi, "Speed and current control for the PMSM using a Luenberger observer," in Proceedings of the International Conference on Multimedia Computing and Systems (ICMCS '11), April 2011.

[41] M. Trabelsi, M. Jouili, M. Boussak, Y. Koubaa, and M. Gossa, "Robustness and limitations of sensorless technique based on Luenberger state-Observer for induction motor drives under inverter faults," in Proceedings $f$ the IEEE International Symposium on Industrial Electronics (ISIE '11), pp. 716-721, June 2011.

[42] Y. Sayed, M. Abdelfatah, M. Abdel-Salam, and S. Abou-Shadi, "Design of robust controller for vector controlled induction motor based on Q-parameterization theory," Electric Power Components and Systems, vol. 30, no. 9, pp. 981-999, 2002.

[43] M. Benosman, "A survey of some recent results on nonlinear fault tolerant control," Mathematical Problems in Engineering, vol. 2010, Article ID 586169, 25 pages, 2010.

[44] BOE 254/2006 P.O. 12.3 Response Requirements of Wind Power Generation to Network Voltage Dips. 


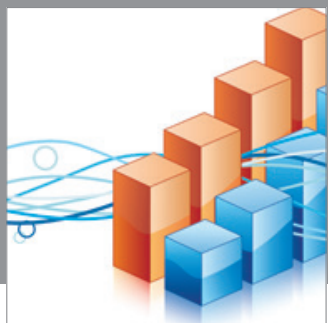

Advances in

Operations Research

mansans

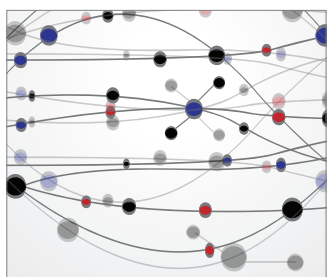

The Scientific World Journal
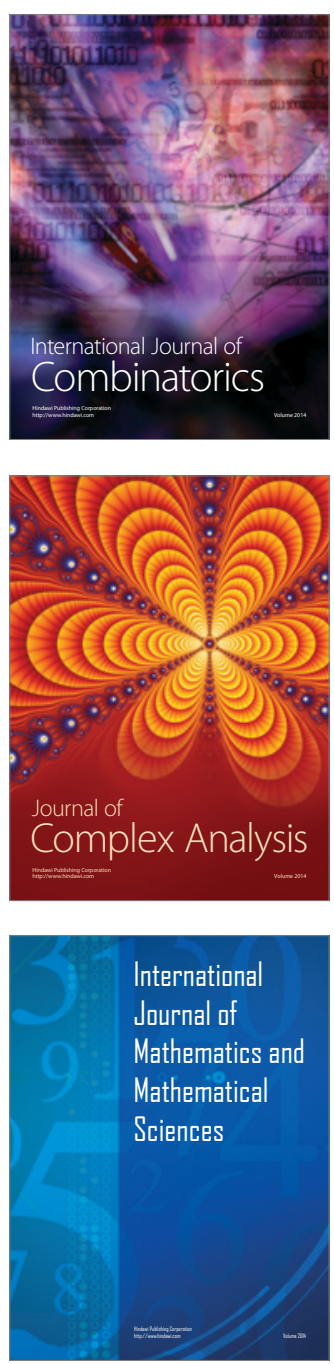
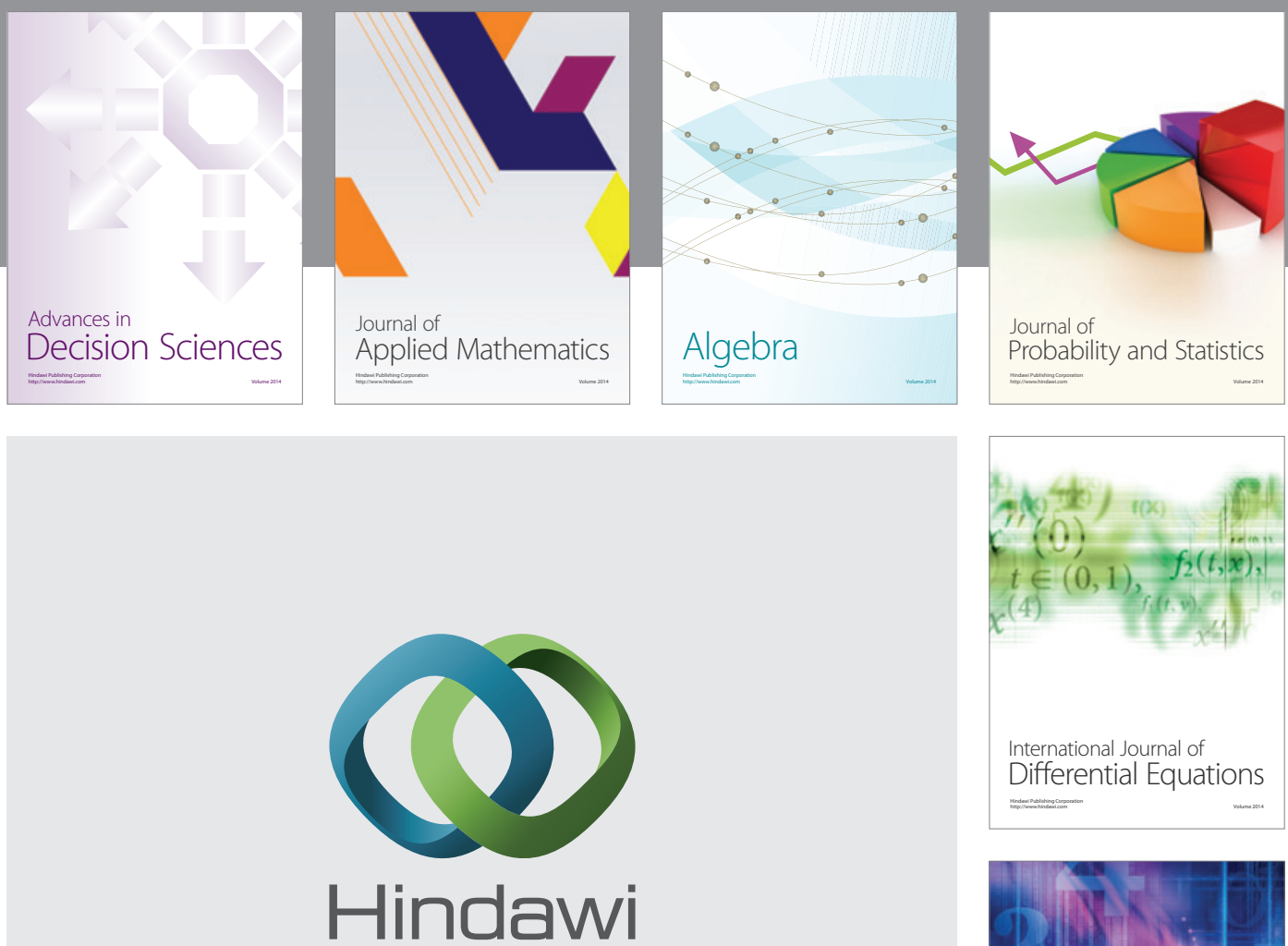

Submit your manuscripts at http://www.hindawi.com
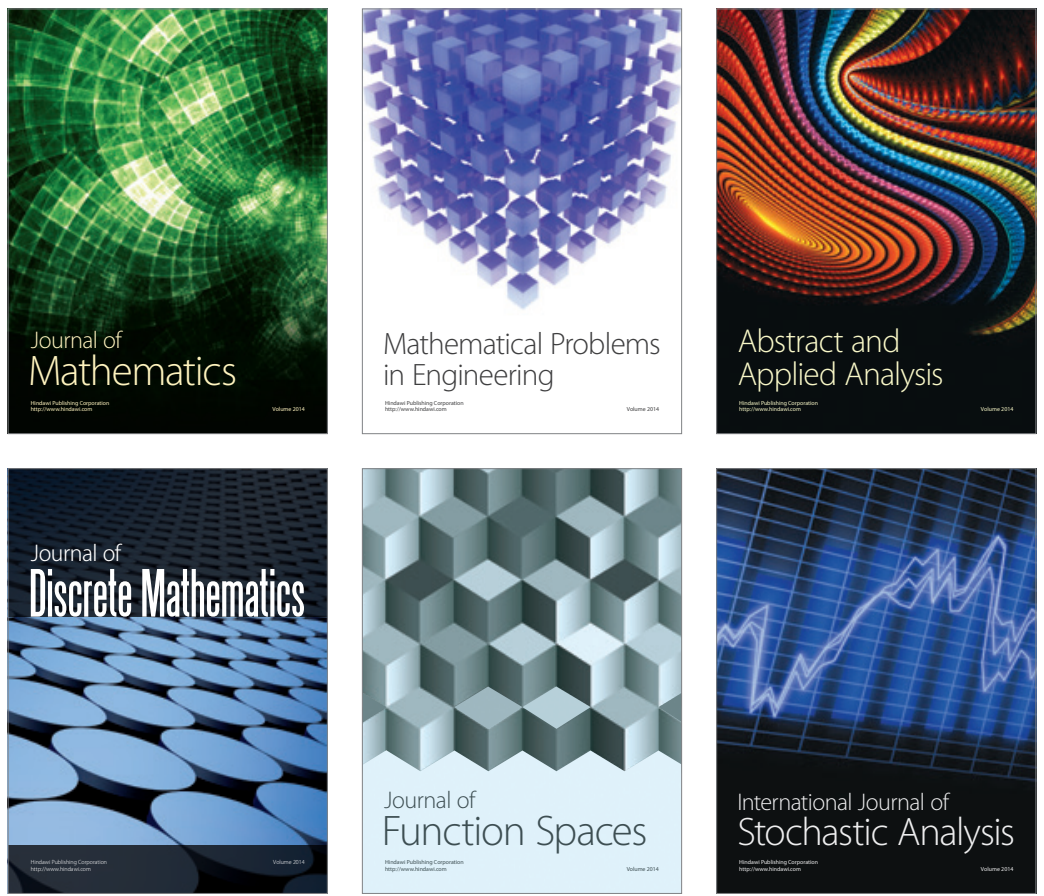

Journal of

Function Spaces

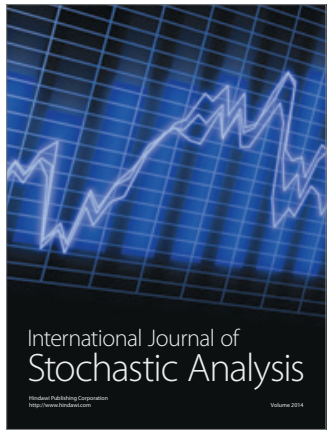

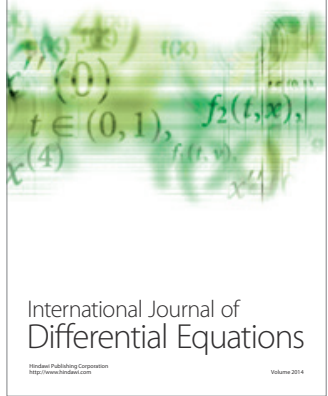
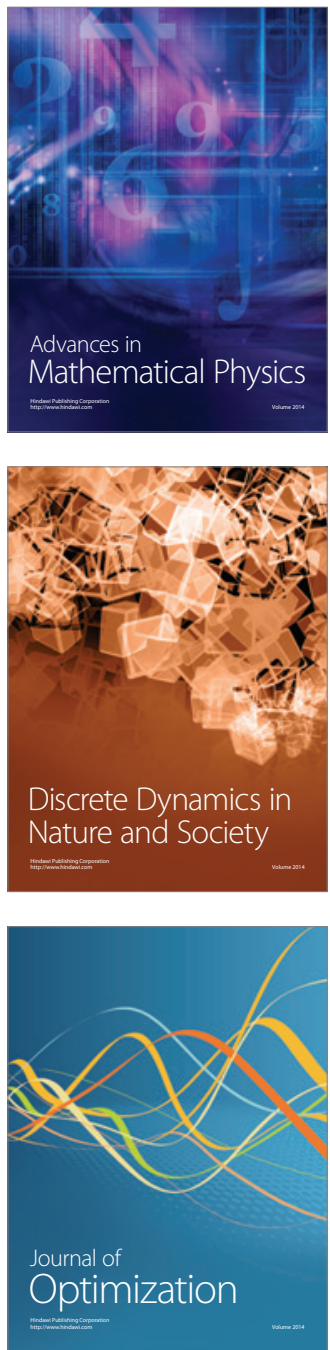